\title{
Influence of Tropical SSTs on the Interannual Variation of the Summer Monsoon Break over the Western North Pacific
}

\author{
KE XU \\ State Key Laboratory of Numerical Modeling for Atmospheric Sciences and Geophysical Fluid Dynamics (LASG), \\ Institute of Atmospheric Physics, Chinese Academy of Sciences, Beijing, China \\ RIYU LU \\ State Key Laboratory of Numerical Modeling for Atmospheric Sciences and Geophysical Fluid Dynamics (LASG), \\ Institute of Atmospheric Physics, Chinese Academy of Sciences, and College of Earth and Planetary \\ Sciences, University of the Chinese Academy of Sciences, Beijing, China

\section{BAEK-JO KIM} \\ Applied Meteorology Research Division, National Institute of Meteorological Sciences, Jeju-do, South Korea

\section{JIANGYU MAO} \\ State Key Laboratory of Numerical Modeling for Atmospheric Sciences and Geophysical Fluid Dynamics (LASG), \\ Institute of Atmospheric Physics, Chinese Academy of Sciences, Beijing, China \\ JONG-KIL PARK \\ Department of Environmental Engineering, and Atmospheric Environment Information Research Center, \\ Inje University, Gimhae, South Korea
}

(Manuscript received 6 May 2018, in final form 12 January 2019)

\begin{abstract}
The break of the western North Pacific (WNP) summer monsoon (WNPSM) occurs climatologically in early August and is accompanied by a remarkable suppression of convection over the ocean east of the Mariana Islands $\left(10^{\circ}-20^{\circ} \mathrm{N}, 140^{\circ}-160^{\circ} \mathrm{E}\right)$. This suppression of convection is sandwiched between two convection peaks in late July and mid-August. Two types of monsoon break are identified in the interannual variation of the WNPSM break in the period 1979-2015, exhibiting a distinct subseasonal evolution of convection that is either in phase or out of phase with the climatological evolution. The preceding SST anomalies in the tropical WNP during early and midJuly are responsible for the interannual variation of the monsoon break. Warm (cold) SST anomalies induce an advanced (delayed) evolution of the WNPSM, with the establishment of strong convection in late July (early August) followed by a monsoon break in early August (mid-August). The subseasonal evolution of convection is therefore in phase (out of phase) with that of the climatological mean. The above SST anomalies mainly result from the local wind-evaporation-SST positive feedback during spring and summer. This local air-sea interaction is still robust after the linear regression components related to the variability of ENSO are excluded from the original fields, indicating that it is, to a large extent, independent of ENSO. The ENSO decaying phases have a secondary role in modulating the SST anomalies related to the WNPSM break.
\end{abstract}

\section{Introduction}

Rainfall is abundant during the monsoon, but often shows clear subseasonal oscillations manifested by the alternation of active and break spells. Monsoon rainfall

Corresponding author: Ke Xu, xuke@mail.iap.ac.cn is reduced remarkably in significant break spells, with the amount of rainfall being similar to that in the premonsoon period (Gadgil and Joseph 2003; Rajeevan et al. 2010). This drastic subseasonal change in precipitation greatly affects social and economic activities by inducing extreme weather events such as floods and droughts. The characteristics of the subseasonal variability 
(such as the frequency, duration, and intensity of the active and break spells) can also affect the seasonal mean intensity of the monsoon (e.g., Fujinami et al. 2011; Goswami and Ajayamohan 2001; Kulkarni et al. 2011; Sharmila et al. 2015). In turn, the seasonal means also affect the subseasonal variability of the monsoon by modulating the behavior of the associated intraseasonal oscillations (e.g., Kulkarni et al. 2009; Sharmila et al. 2015; Singh and Dasgupta 2017). Therefore, studying the monsoon break will help to better understand the monsoon variability on multiple time scales. However, in contrast with the considerable attention that has been paid to the break of the South Asian summer monsoon, the breaks of other monsoons have not been widely studied.

The seasonal march of monsoon rainfall over the South China Sea (SCS) and the western North Pacific (WNP) experiences a stepwise progress (Wu and Wang 2001; LinHo and Wang 2002; Wang and LinHo 2002). The onset of the monsoon takes places over the SCS in midMay and then extends to the southwestern Philippine Sea in mid-June, before progressing abruptly northeastward around late July to the ocean east of the Mariana Islands $\left(10^{\circ}-20^{\circ} \mathrm{N}, 140^{\circ}-160^{\circ} \mathrm{E}\right)$, which is the core region of the WNP summer monsoon (WNPSM). The last onset of the monsoon in late July is accompanied by a drastic enhancement of convection, a phenomenon referred to as the "convection jump" (Ueda et al. 1995; Ueda and Yasunari 1996; Lu et al. 2007; Ueda et al. 2009; Zhou et al. 2016). The convection jump signifies the arrival of the annual peak rainfall over the WNP. In this paper, the term "WNPSM onset" refers to the last onset of the monsoon associated with this convection jump.

$\mathrm{Xu}$ and $\mathrm{Lu}$ (2015) found that, subsequent to this convection jump, there is a distinct monsoon break that occurs climatologically in early August over the ocean east of the Mariana Islands, accompanied by a dramatic rainfall reduction and the suppression of convection. This monsoon break is followed by a recovery in convection in midAugust and the climatological convection therefore shows a notable subseasonal variation after the WNPSM onset. They also noted that this WNPSM break shows large variations from year to year. In about $30 \%$ of years, the monsoon break occurs in early August, featuring consistent subseasonal convection evolution with that of the climatological mean from late July to August. However, in a further $30 \%$ of years the monsoon break is delayed until mid-August and the related subseasonal evolution is out of phase with that of the climatological mean. $\mathrm{Xu}$ and $\mathrm{Lu}$ (2015) attributed these year-to-year variations in the monsoon break and associated convection evolution to the phase shift of 10-25-day oscillations. However, they did not identify the underlying mechanism for the year-to-year variation in the evolution of convection.
Previous studies have suggested that the WNPSM onset, which occurs prior to the monsoon break, is affected by both local and remote SSTs. Ueda et al. (1995) suggested that, in the climatological sense, the appearance of the warm SST tongue in the WNP region provides favorable thermodynamic conditions for the convection jump. Ueda and Yasunari (1996) defined "typical years" of obvious WNPSM onset as when convection is strong during pentads 42 and 43 (25 July3 August) and found that the local SSTs are warmer during early to mid-July in these years. They also noticed that most of the "atypical years" (characterized by weak convection in late July) appear in El Niño years and thus speculated that the interannual variation of the WNPSM onset may be related to the El Niño-Southern Oscillation (ENSO) cycle. Tanaka (1997) defined the monsoon onset based on the atmospheric circulation in late July (20-29 July) and found that the WNPSM onset is related to ENSO, with an earlier onset in La Niña years and a later onset in El Niño years. It should be noted that SST anomalies in the equatorial eastern Pacific in June, rather than winter, which is the season for normal ENSO peaks, were used to define ENSO in Tanaka (1997). Wu and Wang (2000) defined a unified monsoon onset index, including the stepwise onsets from the SCS in May to the WNPSM onset in July. They suggested that this onset index is related to the contrast in SST anomalies between the WNP and the equatorial central Pacific in the previous spring. They also reported that the SST contrast in spring is similar to that in winter due to the persistence of the SST anomalies from winter to spring. In addition to above research focusing on the monsoon onset, the effects of ENSO on the summer rainfall and circulation anomalies in the WNP region have been widely studied (e.g., Wang et al. 2000; Chou et al. 2003; Wu et al. 2009; Chen et al. 2016). An Indowestern Pacific Ocean capacitor (IPOC) mode was proposed to explain this prolonged effect of ENSO: the anticyclonic (cyclonic) anomaly that forms over the WNP at the peak of El Niño (La Niña) can persist to the ensuing summer due to a positive feedback of the Indowestern Pacific ocean-atmosphere interaction (Du et al. 2009; Xie et al. 2009; Xie et al. 2016). Several questions arise from the above research: 1) Is the variability of the WNPSM break in August and the associated subseasonal evolution related to local and remote SSTs and, if so, how do these SSTs affect the interannual variation of the WMPSM break? 2) What are the relative roles of the local and remote SST forcing? These questions are examined in this paper.

In brief, the objectives of this study were to explore the interannual variation of the WNPSM break and to discuss the contributions of local and remote SSTs. The 
organization of this paper is as follows. The data and methods are described in section 2 . In section 3 , we explore the distinct characteristics of convection evolution associated with the monsoon break from year to year. We investigate how the local SSTs in summer modulate this interannual variation in section 4 . The precursory SST anomalies related to the WNPSM break from the preceding seasons are discussed in section 5. Section 6 summarizes our conclusions.

\section{Data and methodology}

Daily outgoing longwave radiation (OLR) data, as a proxy for convection, were obtained from the National Oceanic and Atmospheric Administration (NOAA) satellite. Interpolated OLR data (Liebmann and Smith 1996; www.esrl.noaa.gov/psd/data/gridded/data.interp_ OLR.html) were used for the period of 1979-2013 and uninterpolated OLR data (www.esrl.noaa.gov/psd/data/ gridded/data.uninterp_OLR.html) were used for the period of 2014-2015. The daily horizontal wind, air temperature, geopotential height, and relative humidity at multiple pressure levels were obtained from the National Centers for Environmental PredictionDepartment of Energy (NCEP-DOE) Reanalysis 2 dataset (Kanamitsu et al. 2002) for the period of 19792015. These data have a horizontal resolution of $2.5^{\circ} \times$ $2.5^{\circ}$. The monthly mean rainfall data with the same horizontal resolution were obtained from the Climate Prediction Center Merged Analysis of Precipitation for the period of 1979-2015 (Xie and Arkin 1997).

The daily mean SSTs with a high resolution $\left(0.25^{\circ} \times\right.$ $0.25^{\circ}$ ) were obtained from NOAA optimal interpolation SST datasets (Reynolds et al. 2007) from 1982 to 2015. The daily SST data were interpolated into $1^{\circ} \times 1^{\circ}$ grids using local area averaging. The monthly mean observed SST data from the NOAA/Climatic Diagnostics Center Extended Reconstructed Sea Surface Temperature, version 3 (ERSST. v3; Smith et al. 2008), dataset were also used. The 9-yr running mean was subtracted from the original time series of these daily and monthly SST datasets to remove the long-term signals.

The WNPSM break is tightly connected to the subseasonal evolution of the WNPSM-a convection suppression sandwiched between two convection peaks related to the onset and recovery of the monsoon, respectively (Xu and Lu 2015). This feature not only exists in individual years, but also in the climatological mean. Three stages are defined, corresponding to the periods of the climatological monsoon break and the adjacent convection peaks. Specifically, stage 2 includes 3-8 August (around pentad 44), when the climatological WNPSM break occurs. Stage 1 (24 July-2 August; around pentads 42 and 43) and stage 3 (9-18 August; pentads 45 and 46) cover 10 days prior to, and subsequent to, stage 2, respectively, representing the two climatological convection peaks in late July and midAugust. Following $\mathrm{Xu}$ and $\mathrm{Lu}$ (2015), the monsoon break index is defined as

$$
\begin{aligned}
\operatorname{Index}(i)= & \operatorname{OLR}(i, \text { Stage } 2)-0.5 \times[\text { OLR }(i, \text { Stage } 1) \\
& + \text { OLR }(i, \text { Stage } 3)],
\end{aligned}
$$

where the values of the OLR are averaged over the ocean east of the Mariana Islands $\left(10^{\circ}-20^{\circ} \mathrm{N}, 140^{\circ}-\right.$ $160^{\circ} \mathrm{E}$ ) - the key region of the monsoon break-and $i$ represents the $i$ th year starting from 1979. Accordingly, the break index highlights the variation of convection around early August - the period of the climatological WNPSM break-in each individual year, which, in essence, evaluates the phase-lock extent (or contribution) of subseasonal evolution in that year to the climatological subseasonal evolution. To be more specific, a positive (negative) index indicates that the convection is suppressed (enhanced) in early August relative to the previous and subsequent periods and thus the subseasonal evolution and monsoon break in that particular year tends to be consistent with (distinct from) the climatological conditions.

By emphasizing the variation of convection among the three stages, the present monsoon break index can effectively mitigate the influences from the interannual variation of the seasonal means (the WNPSM is extremely strong in some years, but weak in some other years) and also alleviate the interference from random synoptic disturbances on the estimation of the monsoon break. The deficiency is that the three periods of interest (the monsoon break and the two adjoining convection peaks), which are fixed in the definition, may have different lengths in different years. Therefore, we checked the performance of this index year by year and confirmed that this index is generally suitable during the analysis period of this study.

\section{Characteristics of the interannual variation in the WNPSM break}

Figure 1a shows the time series of the original monsoon break index [black line; same as in $\mathrm{Xu}$ and $\mathrm{Lu}$ (2015) except for an extension of the data to 2015]. This monsoon break shows a large interannual variation. There are more positive (22) than negative (15) years. According to $\mathrm{Xu}$ and $\mathrm{Lu}$ (2015), the positive years are characterized by a monsoon break in early August, consistent with the climatological situation, whereas the negative years are characterized by a delayed monsoon 

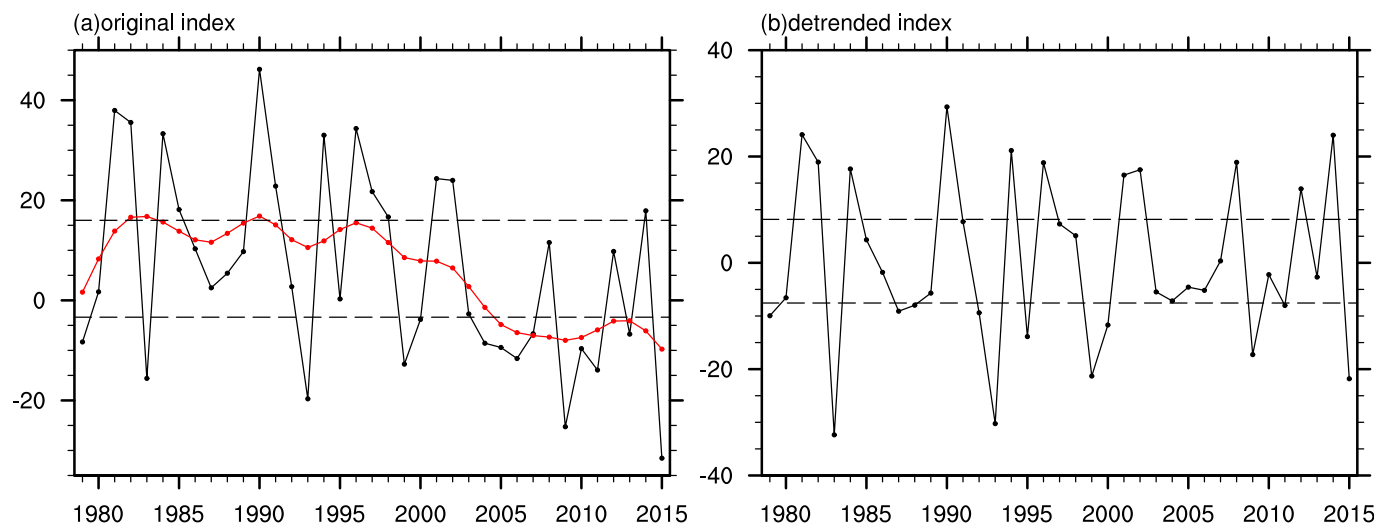

FIG. 1. (a) Time series of the original monsoon break index (black line; $\mathrm{W} \mathrm{m}^{-2}$ ). The smoothed red line is obtained using a 9-yr Gaussian low-pass filter. (b) Detrended monsoon break index obtained by removing the Gaussian-filtered index from the original index. Dashed horizontal lines indicate the \pm 0.5 standard deviations.

break. The monsoon break index has a decreasing trend from the early 2000 s, which is shown more clearly by the 9-yr Gaussian low-pass-filtered index (red line). This decadal change in the monsoon break was explored by $\mathrm{Xu}$ and $\mathrm{Lu}(2018)$.

The Gaussian low-pass-filtered index is removed from the original index to highlight the interannual variation (Fig. 1b). After removing the long-term signal, the variance of the break index is $245.5 \mathrm{~W}^{2} \mathrm{~m}^{-4}$, accounting for $65 \%$ of the original variance. To further explore the features of the interannual variation in the monsoon break, the years when the index exceeds $+0.5(-0.5)$ standard deviations from the average over the entire analysis period are defined as type-A (type-B) cases. This criterion yields 11 type-A cases: 1981, 1982, 1984, 1990, 1994, 1996, 2001, 2002, 2008, 2012, and 2014; and 12 type-B cases: 1979, 1983, 1987, 1988, 1992, 1993, 1995, 1999, 2000, 2009, 2011, and 2015. The other 14 years, which are neither type A nor type B, are classified as residual cases.

Figure 2 shows the longitude-time sections of the OLR averaged between $10^{\circ}$ and $20^{\circ} \mathrm{N}$ for the type-A and type-B cases. The basic characteristics of the evolution of convection in these two types of cases are similar to those of the type-A and type-B years, respectively, in $\mathrm{Xu}$ and $\mathrm{Lu}$ (2015). In brief, from late July to late August (a) Type A

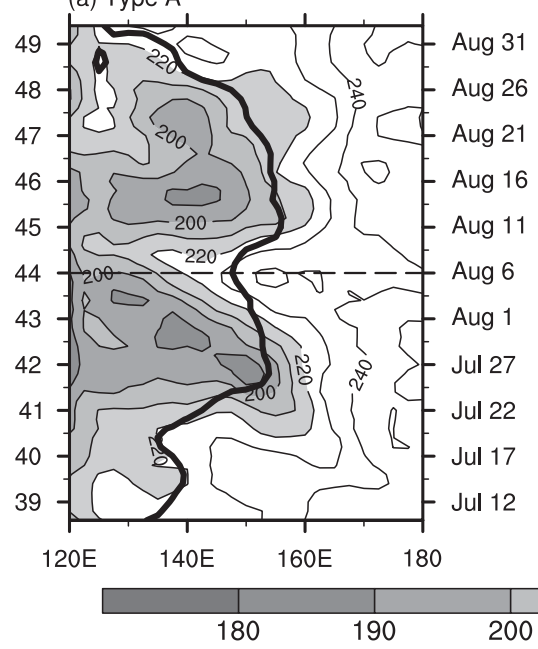

(b) Type B

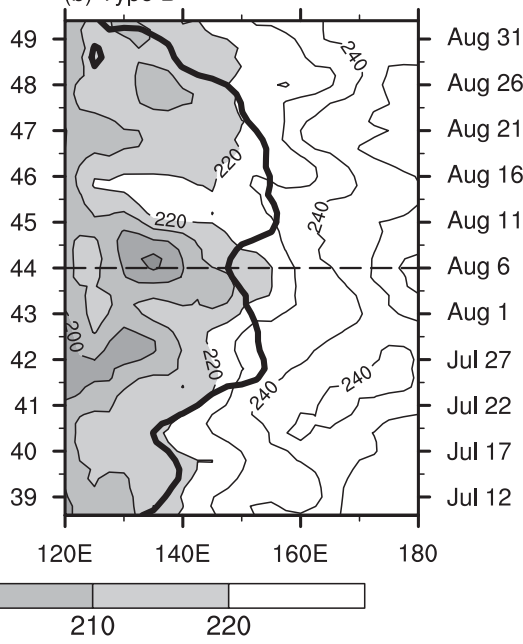

(c) Type A minus Type B

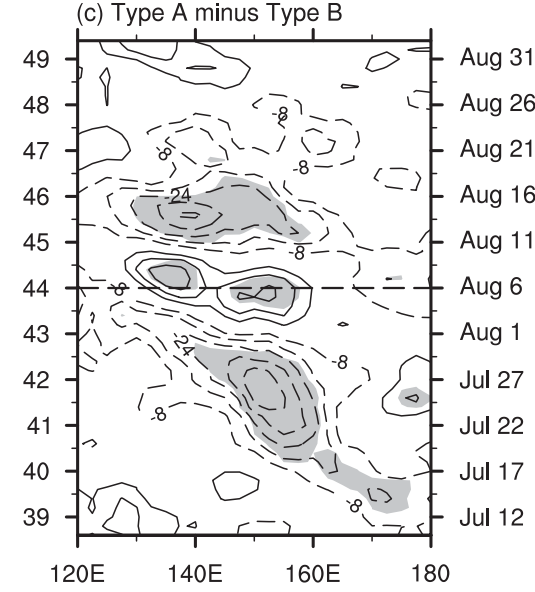

FIG. 2. Longitude-time sections of the 5-day running-mean OLR averaged between $10^{\circ}$ and $20^{\circ} \mathrm{N}$ for the (a) type-A and (b) type-B cases. The contour interval is $10 \mathrm{~W} \mathrm{~m}^{-2}$ and the shading denotes values $<220 \mathrm{~W} \mathrm{~m}^{-2}$. The thick lines denote the contours of $220 \mathrm{~W} \mathrm{~m} \mathrm{~m}^{-2}$ in the climatology. (c) Difference between the type-A and type-B cases. The contour interval is $8 \mathrm{~W} \mathrm{~m}^{-2}$ and the zero contours are omitted. Shading denotes the $95 \%$ confidence level based on a Student's $t$ test. The labels on the left ordinates represent the pentads and those on right represent the middle date of each pentad. The dashed lines represent August 6. 
during the WNPSM, the type-A cases (Fig. 2a) show a remarkable suppression of convection in early August (pentad 44), with the OLR increasing to $>220 \mathrm{~W} \mathrm{~m}^{-2}$ along $140^{\circ}-160^{\circ} \mathrm{E}$, where the key region is located, denoting the occurrence of the monsoon break. This monsoon break is subsequent to the convection peak in late July (pentads 41-42), which is indicated by a drastic decrease in the OLR over the key region, with a minimum center of $190 \mathrm{~W} \mathrm{~m}^{-2}$ at $150^{\circ} \mathrm{E}$, and is followed by a second enhancement of convection in mid-August (pentads 45 and 46). This evolution of convection is consistent with the climatology, which can be derived by comparing the fluctuations of the $220 \mathrm{~W} \mathrm{~m}^{-2}$ contours, except that the monsoon break phenomenon is more prominent and has a larger scope for the type-A cases.

In contrast, the type-B cases show a distinct evolution of convection (Fig. 2b). The convection becomes evidently intensified in early August (pentad 44), when the monsoon break appears in the climatological mean and type-A cases. The subsequent monsoon break is delayed until mid-August (pentads 45-46), the time of the second enhancement of convection in the climatology and type-A cases, indicated by a clear increase of OLR to $>220 \mathrm{~W} \mathrm{~m}^{-2}$ over the region east of $125^{\circ} \mathrm{E}$. This scope of weakened convection is also much larger than that of the climatological monsoon break. The convection is enhanced again in late August (pentads 47 and 48). This evolution of convection suggests a time delay in the evolution of convection for the type-B cases, and thus the evolution of convection seems to be out of phase with that in the climatological mean and type-A cases.

Based on the physical meaning of the monsoon break index (see section 2), the years with positive and negative index extremes are expected to show two typical patterns of subseasonal evolution; namely, being in phase and out of phase with the climatological mean (e.g., the type-A and type-B cases shown in Fig. 2). To validate whether these two types of cases can represent the characteristics of the interannual variation in the WNPSM break, $k$-means cluster analysis (Wilks 2006, 559-560) was performed on the evolution of the WNPSM from late July to late August. The subseasonal evolution of convection can be classified into two clusters, which show highly consistent characteristics with the type-A and type-B cases, respectively, except that the composite amplitudes of the subseasonal evolution for the type-A and type-B cases are slightly larger than those for corresponding clusters (figures not shown). The results of this cluster analysis demonstrate that the monsoon break index can well distinguish the two representative modes of the WNPSM break on an interannual time scale and effectively select the typical cases for each mode (type-A and type-B cases).

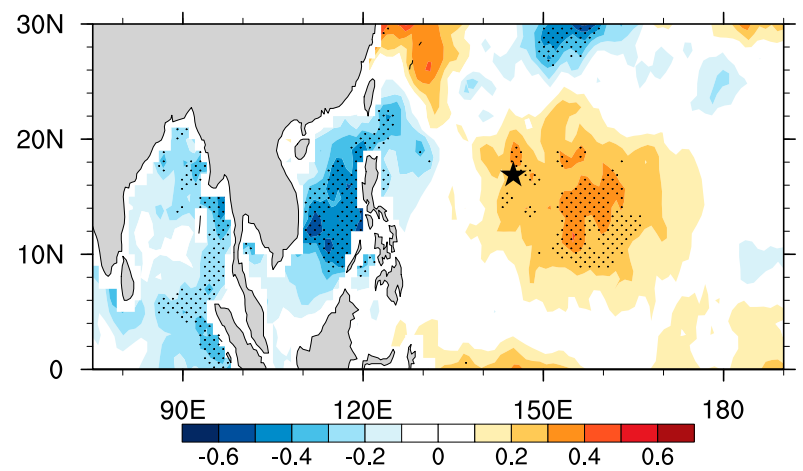

FIG. 3. Differences in SST $\left({ }^{\circ} \mathrm{C}\right)$ during July and August between the type-A and type-B cases. Stippled regions indicate differences greater than the $95 \%$ confidence level according to a Student's $t$ test. The star indicates the location of the Mariana Islands.

The differences in the evolution of convection between the type-A and type-B cases are shown more clearly in Fig. 2c. From mid-July to mid-August, a triple pattern covers $130^{\circ}-160^{\circ} \mathrm{E}$, with a positive difference in early August and two negative differences in late July and mid-August. This significant triple pattern confirms the out of phase evolution of convection between the two types of cases. The significant differences appear mainly during the period from late July to mid-August. On the other hand, it is noted that the negative difference in late July seems to originate from the central Pacific east of $160^{\circ} \mathrm{E}$. In addition, in the original field we can also find the westward propagation of the strong or weak convections for both the type-A and type-B cases (Figs. 2a and 2b). These imply that the subseasonal evolution around the monsoon break may be initialized from the region to the east of the key region.

\section{Influence of local SST anomalies on the WNPSM break}

Figure 3 shows the spatial distribution of the differences in SST averaged for July and August between the type-A and type-B cases. There are significant differences in the tropical WNP, featured by a dipole pattern: the positive differences to the southeast of the Mariana Islands and negative differences in the SCS and along the east coast of the Bay of Bengal (BOB). The significant differences are mainly confined over the latitudes $10^{\circ}-20^{\circ} \mathrm{N}$. These distinct differences in SST between the two types of cases support the speculation that the local and adjacent SST conditions may affect the interannual variation of the WNPSM break.

Figure 4 a shows the longitude-time section of differences in SST between the type-A and type-B cases averaged along $10^{\circ}-20^{\circ} \mathrm{N}$ during July and August. 
(a) type-A minus type-B cases

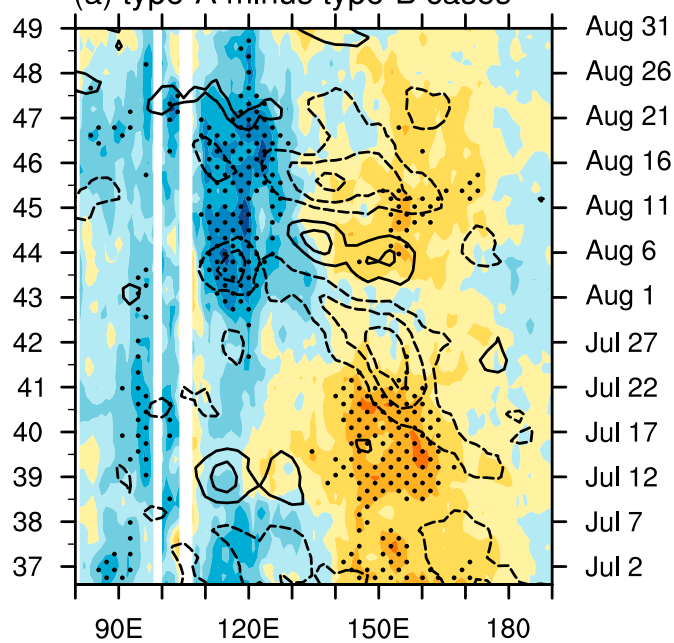

(c) type-B minus residual cases

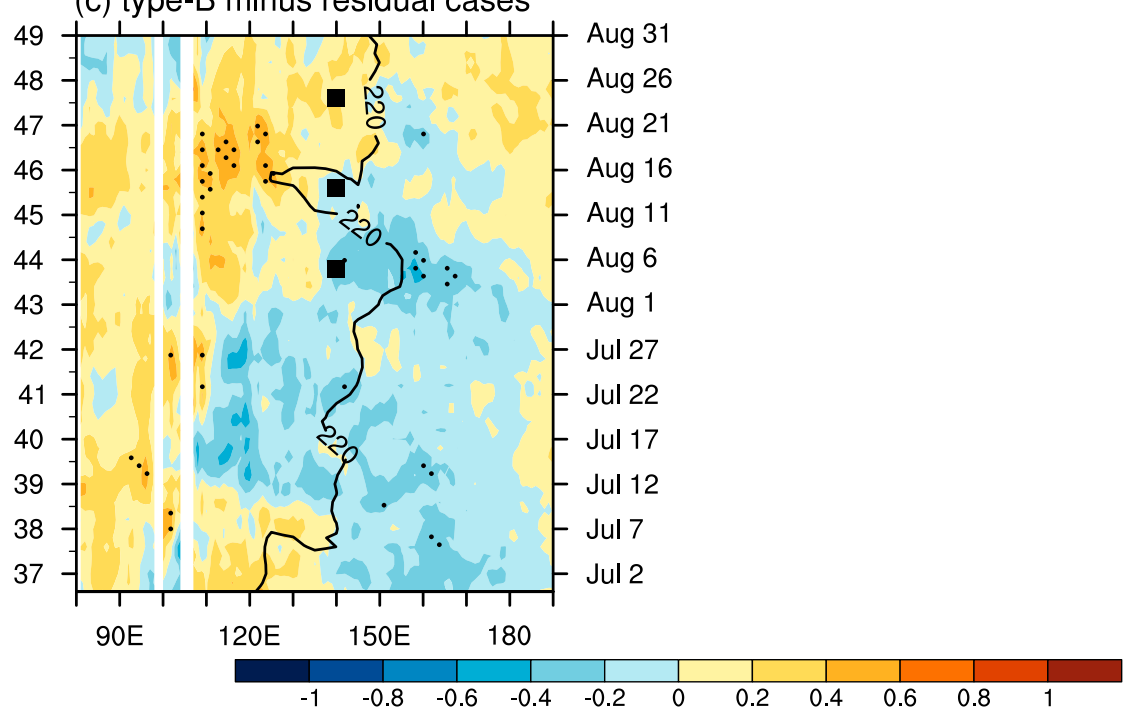

(b) type-A minus residual cases

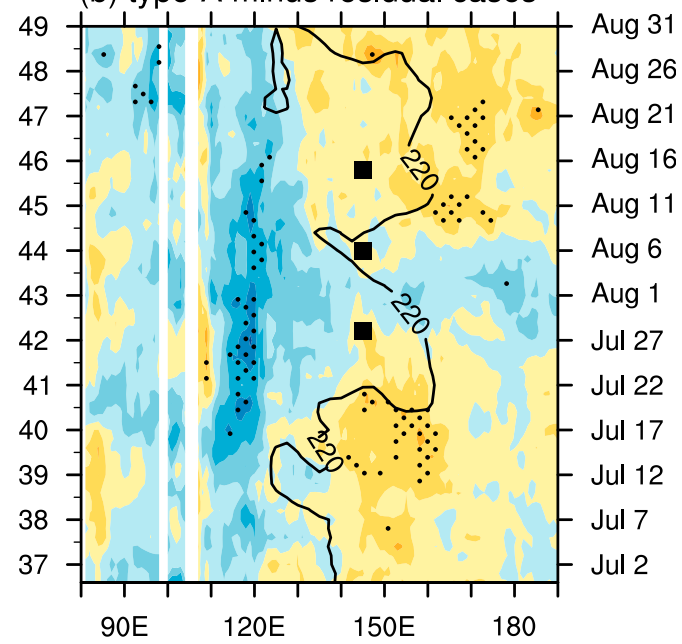

FIG. 4. Longitude-time sections of the differences in SST (colors; ${ }^{\circ} \mathrm{C}$ ) averaged along $10^{\circ}-20^{\circ} \mathrm{N}$ between the (a) type-A and type-B cases, (b) type-A and residual cases, and (c) type-B and residual cases. Stippled regions indicate differences greater than the $95 \%$ confidence level according to a Student's $t$ test. The difference in OLR (contours; $\mathrm{W} \mathrm{m}^{-2}$ ) between the type-A and type-B cases as in Fig. $2 \mathrm{c}$ is also shown in (a) with a contour interval of $12 \mathrm{~W} \mathrm{~m}^{-2}$. Contours of $220 \mathrm{~W} \mathrm{~m}^{-2}$ of OLR for the type-A and type-B cases (as in Figs. $2 \mathrm{a}$ and $2 \mathrm{~b}$ ) are also shown in (b) and (c), respectively. The square symbols in (b) and (c) denote the three stages of monsoon onset, break, and recovery for the type-A and type-B cases, respectively.

The difference in OLR as in Fig. 2c is also shown in Fig. 4a. It shows that a significant positive difference in SST appears in the WNP during early and mid-July (pentads 37-41), the period of weak convection over the WNP, with an amplitude of $>0.4^{\circ} \mathrm{C}$ covering $140^{\circ}-$ $170^{\circ} \mathrm{E}$. During the period from the end of July to late August, when strong convection has been established over the WNP, the positive SST difference is weakened and fluctuates with convection. Specially, as the negative difference in OLR intensifies at pentad 42, the positive difference in SST notably weakens at pentads $42-43$ and then intensifies slightly at pentads 44-45 subsequent to the positive difference in OLR. By contrast, the SST differences in the BOB and SCS are weak during July: there is a marginally significant negative difference confined within $90^{\circ}-100^{\circ} \mathrm{E}$, and an insignificant difference along $110^{\circ}-120^{\circ} \mathrm{E}$. The negative SST difference in the SCS is intensified until August. Therefore, the preexisting positive SST difference in the WNP during early and mid-July may be crucial in the subsequent distinct break-related evolution of convection, whereas the SST difference in the SCS during 
August may be the response to the distinct evolution of convection.

The SST difference between the type-A (type-B) and residual cases was investigated further in Fig. $4 \mathrm{~b}$ (Fig. 4c). The contour of $220 \mathrm{~W} \mathrm{~m}^{-2}$ of OLR for the type-A (type-B) cases as in Fig. 2a (Fig. 2b) is also shown to depict the evolution characteristics of convection. A positive SST difference is found in the WNP between the type-A and residual cases (Fig. 4b) and shows characteristics consistent with those in Fig. 4a. A significant positive SST difference appears during pentads $37-41$ and then disappears at pentads $42-43$, corresponding to enhanced convection for the type-A cases, and subsequently intensifies again, but with less significance. The negative SST difference in the SCS is significant during pentads $41-46$, the period in which convection obviously fluctuates over the WNP for the type-A cases, which further implies that the SST difference in the SCS may be a response to the anomalous evolution of convection over the WNP. The SST difference is weak during July and August in the BOB.

For the SST difference between the type-B and residual cases (Fig. 4c), a significant negative difference appears in the WNP during pentads 37-41, in contrast with the positive difference between the type-A and residual cases (Fig. 4b). These significant opposite differences in SST (Figs. 4b and 4c) further confirm their influence on the interannual variation of the WNPSM break. By contrast, the SST differences in the BOB and SCS are weak during the same period. The negative SST difference in the WNP intensifies at pentad 44 as convection enhances for the type-B cases, then weakens in mid-August while a positive difference appears in the SCS.

Considering that the preceding differences in SST during early and mid-July in the WNP are probably a fundamental factor leading to the interannual variation of the monsoon break, an SST index (SSTI) is defined as the SST anomalies averaged over pentads $37-41$ and the region $\left(10^{\circ}-20^{\circ} \mathrm{N}, 140^{\circ}-170^{\circ} \mathrm{E}\right)$. The time series of the normalized SSTI and monsoon break index are shown in Fig. 5. There is a good correspondence between the two indices with a correlation coefficient of 0.51 . To further explore how the SST anomalies exert an influence on the monsoon break, we define years when the SSTI exceeds $+0.5(-0.5)$ standard deviations as warm (cold) cases and then examine the changes in convection and circulation by performing a composite analysis based on the selected SSTI cases. This criterion yields 10 warm cases (1984, 1989, 1990, 1991, 1994, 1996, 2001, 2007, 2009, 2014) and 12 cold cases $(1983,1986,1987,1992$, 1993, 2000, 2002, 2006, 2010, 2011, 2012, 2015).

Figure 6 shows the differences between the warm and cold cases during early and mid-July (pentads 37-41).

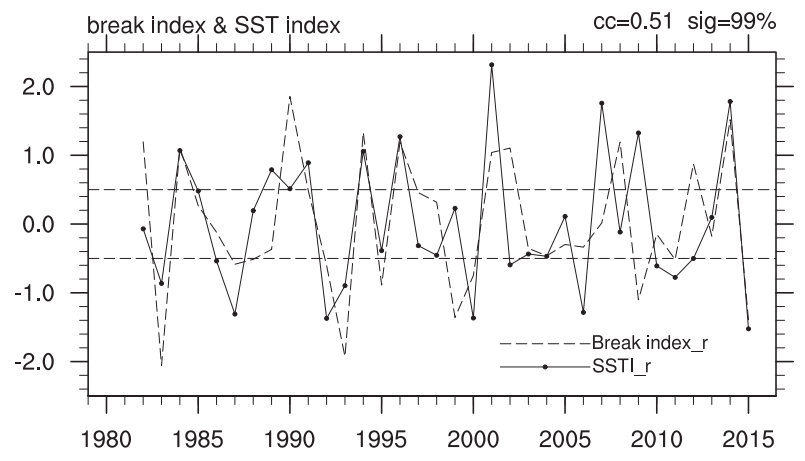

FIG. 5. Time series of the normalized SST index (solid line; see text for definition). Dashed horizontal lines indicate \pm 0.5 standard deviations. The normalized monsoon break index of Fig. 1b is also shown (dashed line) to facilitate comparison.

There is a significant positive SST difference in the WNP with a center over $0.6^{\circ} \mathrm{C}$ to the east of the Mariana Islands, whereas the SST difference is weak in the SCS (Fig. 6a). This pattern of SST differences is similar to that between the type-A and type-B cases (figure not shown). Corresponding to the positive SST difference, a negative difference in atmospheric instability appears over the WNP, with large magnitudes to the east of the Mariana Islands (Fig. 6b). Here, the atmospheric instability is estimated as the difference in the equivalent potential temperature $\theta_{e}$ between 700 and $1000 \mathrm{hPa}$ (Roxy and Tanimoto 2007; Wu 2010) and a negative instability indicates that the lower troposphere is unstable. The correspondence between the differences in SST and instability suggests that the SST affects convection by modifying atmospheric instability, in agreement with previous studies (Ueda and Yasunari 1996; Wu and Wang 2001; Roxy and Tanimoto 2007; Wu 2010; Jiang and Li 2011; Li et al. 2016).

Figure $6 \mathrm{c}$ shows the longitude-time section of the differences in atmospheric instability (colors) and OLR (contours) averaged along $10^{\circ}-20^{\circ} \mathrm{N}$ between the warm and cold cases. Corresponding to the warm SST difference in early and mid-July (Fig. 4a), a negative difference in atmospheric instability is observed to the east of $150^{\circ} \mathrm{E}$, favoring the development of convection. As a consequence, the negative difference in OLR originates from the negative atmospheric instability center at pentad 41, and then propagates westward, leading to the establishment of strong convection over the WNP. This configuration suggests that the anomalous atmospheric instability to the east of the key region, which is attributable to the SST anomalies, is crucial in the initiation of the deep convection related to the onset of the WNPSM. The convection shows a triple pattern of oscillation during late July-mid-August, corresponding to the convection enhancement, break, and recovery, respectively. 
(a) SST differnce

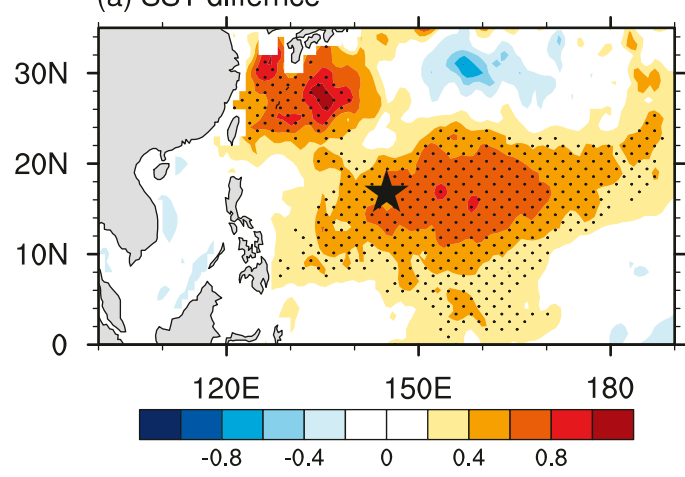

(c) warm minus cold cases

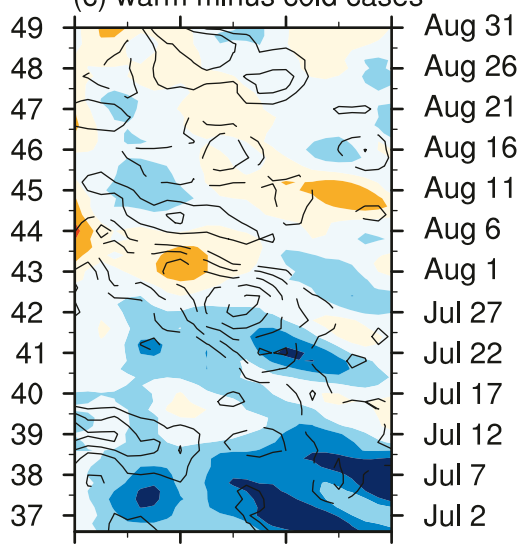

(b) atmospheric instability difference

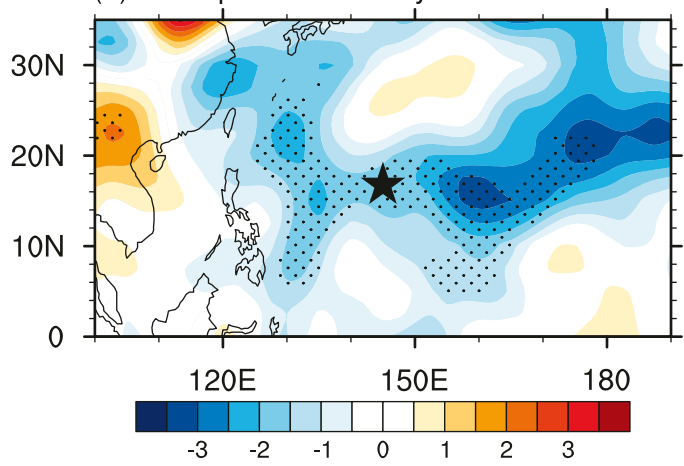

(d) type-A minus type-B cases

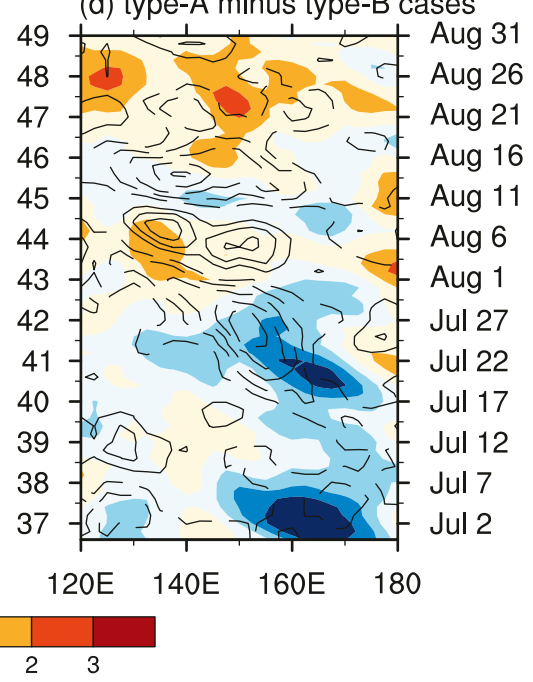

FIG. 6. (top) Differences in (a) SST $\left({ }^{\circ} \mathrm{C}\right)$ and (b) atmospheric instability (K) during early and mid-July (pentads $37-41$ ) between the warm and cold cases. Stippled regions indicate differences greater than the $95 \%$ confidence level according to a Student's $t$ test. The star indicates the location of the Mariana Islands. (bottom) Longitude-time sections of atmospheric instability difference (colors; K) and OLR difference (contours; $\mathrm{W} \mathrm{m}^{-2}$ ) averaged along $10^{\circ}-20^{\circ} \mathrm{N}$ between the (c) warm and cold cases and the (d) type-A and type-B cases. The contour interval is $8 \mathrm{~W} \mathrm{~m}^{-2}$ and the zero contours are omitted.

These differences between the warm and cold cases are similar to those between the type-A and type-B cases (Fig. 6d). The resemblance confirms that the preceding SST anomalies contribute to the subsequent distinct phase changes of the WNPSM by adjusting atmospheric stability.

\section{Precursory SST anomalies related to the WNPSM break}

The results in section 4 suggest that the interannual variation of the monsoon break is associated with the SST anomalies in the tropical WNP in July. To understand the origin of these SST anomalies, the SST differences between the warm and cold cases are shown from the preceding winter to summer (Fig. 7). The positive difference in SST emerges in the tropical western Pacific in the preceding winter. This positive difference is then enhanced, accompanied by a northeastward extension, in the following spring. In early and midsummer, the positive SST difference covers $10^{\circ}-20^{\circ} \mathrm{N}$, where the key region is located.

In addition to the local SST anomalies, there are also remote anomalies in the equatorial central and eastern Pacific. The negative difference in SST appears in the equatorial central and eastern Pacific in the preceding winter. The difference is marginally significant in the central Pacific, but is weak in the eastern Pacific. In the following spring, the negative SST difference is intensified in the eastern Pacific. This negative difference then gradually shrinks eastward and disappears in midsummer. These SST anomalies show distinct differences 
(a)
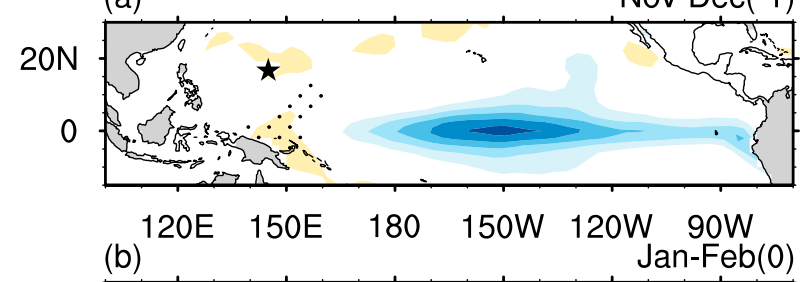

$20 \mathrm{~N}$

0

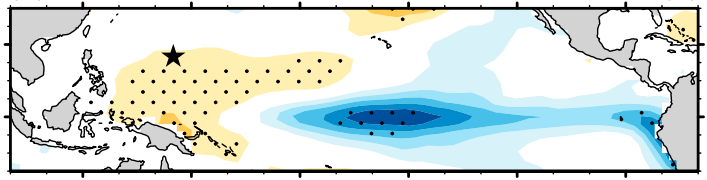

(c)

$20 \mathrm{~N}$

0

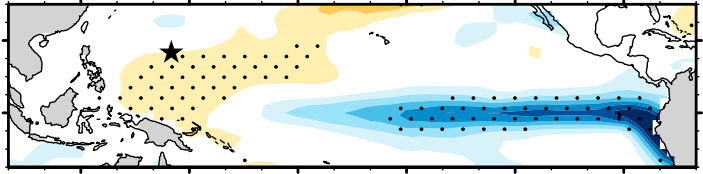

(d)

$20 \mathrm{~N}$

0
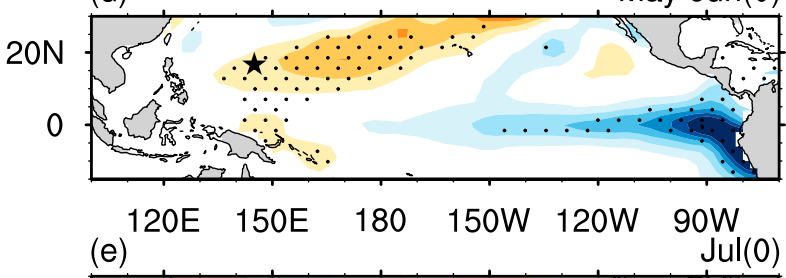

$20 \mathrm{~N}$

0

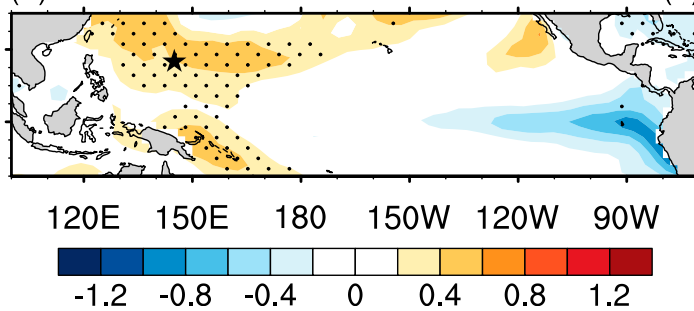

FIG. 7. Spatial distribution of differences in $\mathrm{SST}\left({ }^{\circ} \mathrm{C}\right)$ between the warm and cold cases. The "0" refers to the year of monsoon break and the " -1 " refers to the previous year. Stippled regions indicate the $95 \%$ confidence level according to a Student's $t$ test. The stars indicate the location of the Mariana Islands.

from the SST anomalies related to the onset of the WNPSM in previous studies. The evolution of SST shown in Fig. 7 indicates that the warm SST anomalies in the WNP during midsummer persist from the preceding winter. The cooling of the SST in the eastern Pacific may also contribute to the midsummer warm SST anomalies in the WNP.

Figure 8 shows the differences in precipitation and lower-tropospheric wind anomalies during May-July between the warm and cold cases. The evolution of these differences was also examined month by month and showed common features to those in Fig. 8, thus only the May-July averaged results are shown here for (a) precipitation $\operatorname{MJJ}(0)$

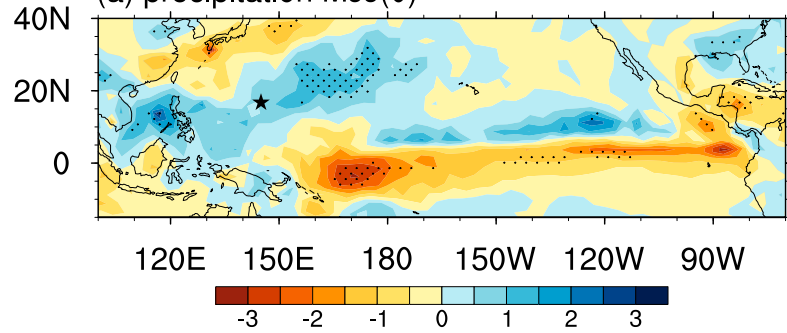

(b) UV850 MJJ(0)

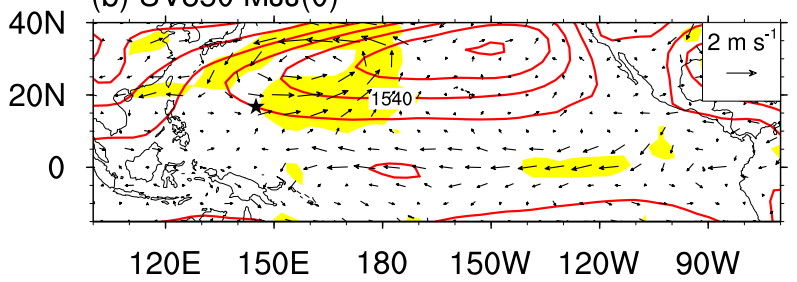

FIG. 8. Spatial distributions of (a) precipitation difference $\left(\mathrm{mm} \mathrm{day}^{-1}\right)$ and (b) $850-\mathrm{hPa}$ wind difference $\left(\mathrm{m} \mathrm{s}^{-1}\right)$ averaged during May-July between the warm and cold cases. The red contours in (b) indicate the climatological mean geopotential height with a contour interval of $20 \mathrm{gpm}$. Stippled regions in (a) and yellow shading in (b) denote the $95 \%$ confidence level based on a Student's $t$ test. The stars indicate the location of the Mariana Islands.

simplicity. Corresponding to the cold SST difference, a negative difference in precipitation is observed along the equatorial Pacific east of $160^{\circ} \mathrm{E}$. Concurrently, a band of positive precipitation difference extends northeastward from the tropical western Pacific to the subtropical North Pacific, corresponding to the underlying positive SST difference. There is a cyclonic anomaly located to the northwest of the positive precipitation anomaly, suggesting a Rossby wave response to the enhanced convective heating (Gill 1980). The anomalous southwesterly winds in the southeast of the cyclonic anomaly $\left(10^{\circ}-25^{\circ} \mathrm{N}\right)$ are superposed on the mean easterly winds related to the subtropical high (red contours in Fig. 8b). Therefore the total wind speed and the associated evaporation and entrainment cooling are weakened, which favors in situ warming of the SST. This wind-evaporation-SST feedback has been widely adopted in air-sea interactions (e.g., Xie and Philander 1994; Wang et al. 2000, 2003). There is also a positive feedback between the circulation and precipitation anomalies. The cyclone-related southwesterly winds may enhance the transportation of moisture to the WNP, contribute to the positive precipitation anomaly and thereby further intensify the cyclonic anomaly. Through these positive feedbacks, the warm SST difference in the WNP persists through the spring and summer. It should be mentioned that the positive windevaporation-SST feedback does not work during the 
period of WNPSM, when a negative feedback between the SST and convection is dominant as discussed in Fig. 4, because the prevailing easterly winds over the subtropical WNP are much weakened in association with the remarkable eastward retreat of the subtropical high after WNPSM onset.

The negative SST differences in the equatorial central and eastern Pacific during the preceding winter and spring (Fig. 7) are reminiscent of ENSO. Therefore, the Niño-3.4 index - that is, the SST anomalies averaged over the region $5^{\circ} \mathrm{S}-5^{\circ} \mathrm{N}, 170^{\circ}-120^{\circ} \mathrm{W}$ during the preceding winter (December-February) - are used to represent the ENSO cycle, considering that ENSO generally reaches its mature stage in winter. The correlation coefficient between this preceding winter Niño-3.4 index and the July SSTI is -0.33 , which is statistically significant at the $94 \%$ confidence level. To illustrate the relative roles of the local process and ENSO in affecting the midsummer SST anomalies in the WNP, the SST and circulation anomalies are regressed onto the SSTI after removing the influence of the negative Niño-3.4 indexthat is, the linear regression coefficients of the SST and circulation fields onto the negative Niño-3.4 index are first calculated and the regression components (regression coefficients multiplied by the negative Niño-3.4 index) are then removed from the original SST and circulation fields. Then, the regression analysis is performed using the new SST and circulation fields. The method of removing ENSO can illustrate the SSTI-related anomalies independent of ENSO, which may be useful if we consider that the extensive impacts of ENSO may be confused with the anomalies of interest (Chen et al. 2015).

Figures 9a-e show the evolution of the SST anomalies regressed onto the SSTI after excluding the impact of the negative Niño-3.4 index. The negative SST anomalies in the equatorial central and eastern Pacific are considerably weakened compared with the original SST differences shown in Fig. 7, which is expected because the ENSO-related variability has been removed. The positive anomalies in the WNP from the preceding November to April disappear, implying that these SST anomalies are influenced by the ENSO cycles. Significant positive SST anomalies subsequently appear in the WNP from May to July, showing a high similarity with the original SST difference (Fig. 7). This suggests that the positive SST anomalies from May to July tend to be independent of ENSO and that they are the result of local air-sea interactions. However, it should be mentioned that the weak negative SST anomalies in the equatorial eastern Pacific tend to develop in the following autumn and winter (not shown).

Figures 9f-j show the regression of the SST anomalies onto the negative Niño-3.4 index as a comparison with the ENSO-related anomalies. The SST anomalies show the typical pattern of a La Niña decaying phase. Significant positive SST anomalies appear in the WNP in the preceding winter and persist into the spring. This further confirms that the positive SST difference in the WNP during the preceding winter and spring (Fig. 7) is related to the variability of ENSO. However, the positive SST anomalies are weak in the WNP in July, suggesting that ENSO plays a secondary part in affecting the subsequent SSTs in the WNP.

Figure 10a shows the regression of the May-July mean precipitation anomalies onto the SSTI after eliminating the impact of ENSO. Compared with the original field (Fig. 8a), the negative precipitation anomalies along the equatorial Pacific become insignificant, corresponding to considerably weakened negative SST anomalies after removing the ENSO signal (Figs. 9d and 9e). By contrast, significant positive precipitation anomalies appear over the WNP, with a weakened intensity relative to the original precipitation difference (Fig. 8a). The positive precipitation anomalies stimulate a cyclonic anomaly to the northwest, which is highly consistent with the original wind difference (Fig. 8b). The correspondence of the precipitation and wind anomalies with the original fields shows that the local process of positive feedback between the air and sea is robust after removing the impact of ENSO. Through this local process, the SST anomalies can be maintained from May to July (Figs. 9d and 9e).

The weakness of the positive precipitation anomalies in Fig. 10a, relative to the original anomalies shown in Fig. 8a, suggests that ENSO may also affect air-sea interactions in the WNP. Figures 10c and 10d show the regression of the May-July mean precipitation and circulation anomalies onto the negative Niño-3.4 index. Significant positive precipitation anomalies are found over the SCS and the Philippine Sea and extend northeastward into the WNP. Correspondingly, a significant cyclonic anomaly appears to the northwest of the positive precipitation anomalies. These precipitation and wind anomalies related to ENSO are similar to the anomalies related to the SSTI (Figs. 10a and 10b) to the northeast of the Mariana Islands, confirming that ENSO can affect air-sea interactions in this region. By contrast, the significant positive precipitation anomalies in the SCS and Philippine Sea, and the associated cyclonic anomaly, are unique to ENSO (Figs. 10c and 10d) and do not exist for the SSTI (Figs. 10a and 10b). These precipitation and circulation anomalies associated with ENSO have been well documented (e.g., Wu et al. 2003; Wu et al. 2009; Xie et al. 2009; Chen et al. 2014, 2016; Li et al. 2014).

Different mechanisms may be responsible for the positive precipitation anomalies over the tropical WNP 
SSTI remove ENSO
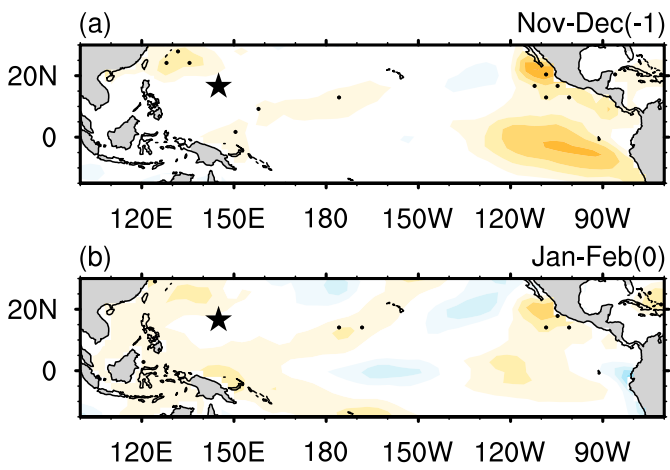

(c)
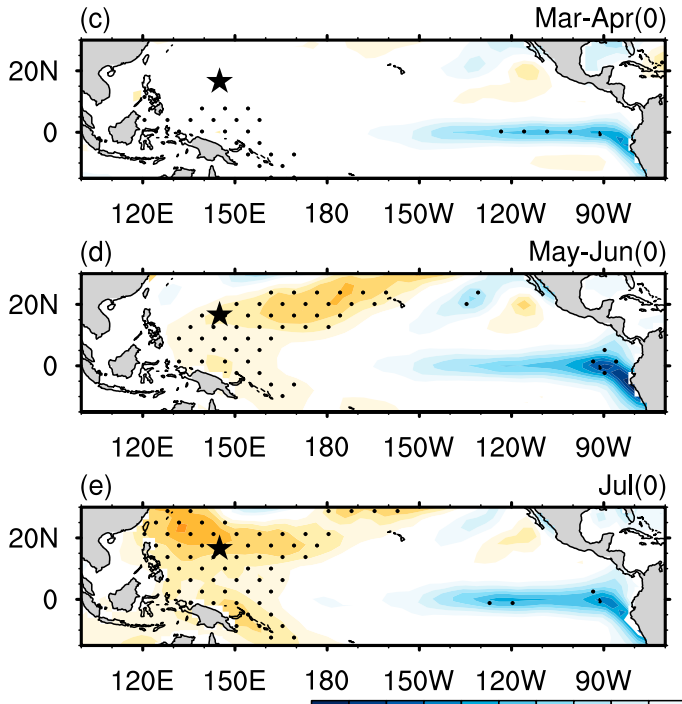
$\mathrm{Jul}(0)$

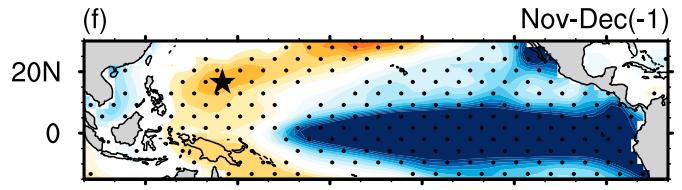

120E 150E 180 150W 120W 90W

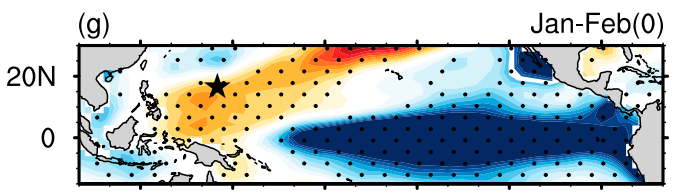

120E 150E 180 150W 120W 90W
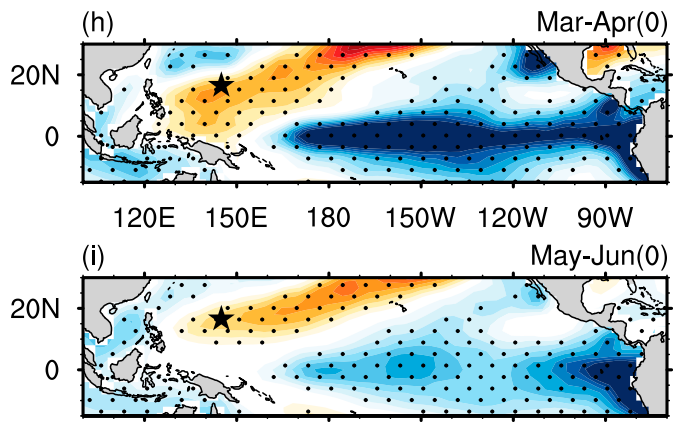

$120 \mathrm{E} \quad 150 \mathrm{E} \quad 180 \quad 150 \mathrm{~W} 120 \mathrm{~W}$ 90W

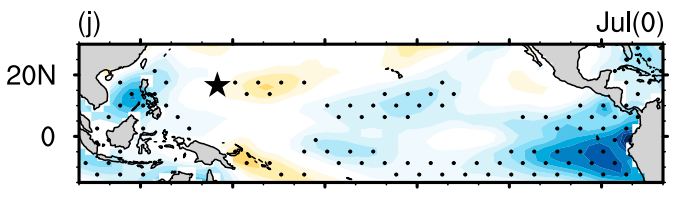

$120 \mathrm{E} \quad 150 \mathrm{E} \quad 180$ 150W 120W 90W

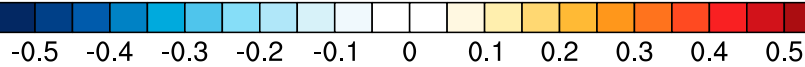

FIG. 9. Regression of the SST anomalies $\left({ }^{\circ} \mathrm{C}\right)(\mathrm{a})-(\mathrm{e})$ onto the SSTI after removing the impact of the negative Niño-3.4 index and (f)-(j) onto the negative Niño-3.4 index. See text for details of the method for removing the impact of ENSO. The " 0 " refers to the year of monsoon break and the " -1 " refers to the previous year. Stippled regions indicate the $90 \%$ confidence level according to a Student's $t$ test. The stars indicate the location of the Mariana Islands.

(the SCS and the Philippine Sea) and the subtropical WNP (to the northeast of the Mariana Islands), although they are merged together in Fig. 8. The enhanced rainfall corresponds to the underlying warmer SSTs to the northeast of the Mariana Islands, but to the cooler SSTs in the SCS and Philippine Sea. The positive local SST-precipitation relationship to the northeast of the Mariana Islands suggests that SSTs may play an active part in the air-sea interactions, with the ocean forcing the atmosphere (Kumar et al. 2013). This mechanism was suggested in the preceding section and is partially in agreement with that proposed by Wang et al. (2000). Actually, the SST-precipitation correlation shows a distinct spatial distribution in the WNP during summer, being negative in most of the WNP, but tending to be positive to the northeast of the Mariana Islands (Trenberth and Shea 2005; Wang et al. 2005; Wu et al. 2006; Wu et al. 2009; $\mathrm{Lu}$ and $\mathrm{Lu}$ 2014). The negative SST-precipitation correlation suggests that the atmosphere forces the ocean over most of the WNP (Kumar et al. 2013) and the atmospheric variability is affected by remote SST anomalies, including the Indian Ocean (Terao and Kubota 2005; Yang et al. 2007; Li et al. 2008; Yun et al. 2008; Xie et al. 2009; Huang et al. 2010; Kosaka et al. 2013), the tropical central and eastern Pacific (Lau and Nath 2006; Wang et al. 2013; $\mathrm{Lu}$ and $\mathrm{Lu}$ 2015), and the tropical Atlantic (Hong et al. 2014; Chen et al. 2015).

Considering that our conclusions are derived based on the ENSO-removing method by linear regression, another method was also used to eliminate the impact of ENSO. Specifically, the cases with evident ENSO signals (DJF Niño-3.4 index exceeding \pm 0.6 standard 
(a) precip_SSTI_remove_ENSO

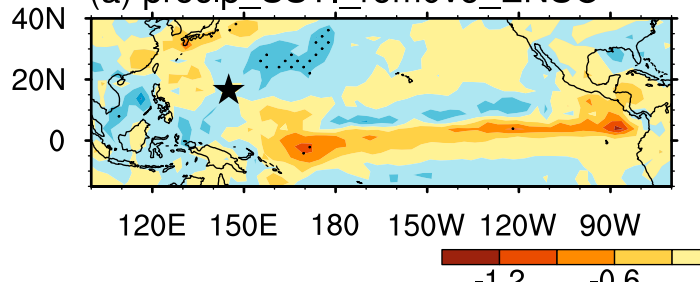

(c) precip_-Nino3.4(D-1JF0)

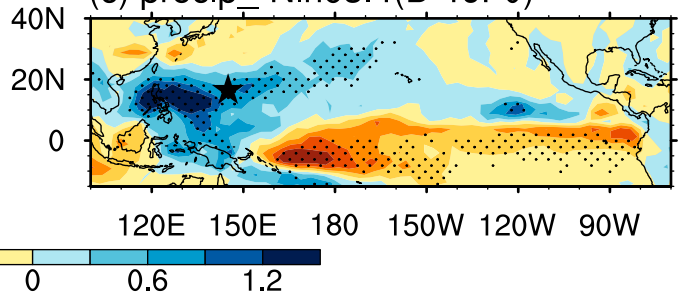

(d) UV850_Nino3.4(D-1JF0)

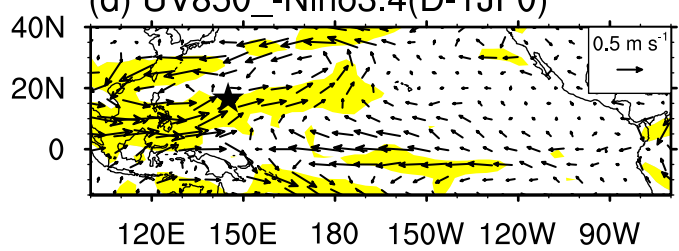

120E 150E 180 150W 120W 90W

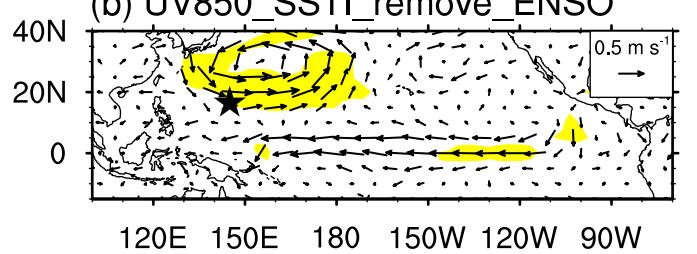

FIG. 10. (left) Regression of May-July mean (a) precipitation anomalies $\left(\mathrm{mm} \mathrm{day}^{-1}\right.$ ) and (b) 850-hPa wind anomalies $\left(\mathrm{m} \mathrm{s}^{-1}\right)$ onto the SSTI after removing the impact of the negative Niño-3.4 index. (right) Regression of May-July mean (c) precipitation anomalies $\left(\mathrm{mm} \mathrm{day}^{-1}\right.$ ) and (d) $850-\mathrm{hPa}$ wind anomalies $\left(\mathrm{m} \mathrm{s}^{-1}\right)$ onto the negative Niño-3.4 index. Stippled regions in (a) and (c) and yellow shading in (b) and (d) denote the $95 \%$ confidence level based on a Student's $t$ test. The stars indicate the location of the Mariana Islands.

deviations) were removed from the warm and cold cases and the differences in SST, precipitation and $850-\mathrm{hPa}$ wind were composited between the residual warm (5 years) and cold (4 years) cases. The results (figures not shown) show consistent features with those obtained via partial linear regression (Figs. 9a-e, 10a, and 10b), indicating that the present result on the role of local airsea interactions in affecting the WNPSM break is robust and is not dependent on the methods used to remove the effects of ENSO.

\section{Conclusions}

This study investigated the interannual variation of the WNPSM break over the past 37 years (19792015). Two types of monsoon break (type-A cases and type-B cases) are identified that show distinct evolutions of convection. The influences of tropical SSTs on the WNPSM break are explored, including the local SST anomalies in the tropical western Pacific and remote SST anomalies in the central and eastern Pacific.

The subseasonal evolution of convection related to the monsoon break shows out of phase characteristics between type-A and type-B cases. Specifically, the monsoon break occurs in early August in type-A cases, accompanied by a remarkable suppression of convection over the ocean east of the Mariana Islands $\left(10^{\circ}-20^{\circ} \mathrm{N}, 140^{\circ}-160^{\circ} \mathrm{E}\right)$. This suppression is sandwiched between two convection peaks in late July and mid-August, which are associated with the onset and recovery, respectively, of the WNPSM. This evolution of convection is in phase with the climatological evolution, except that the suppression of convection during the break period is more prominent in type-A cases. By contrast, the monsoon break in type-B cases occurs in mid-August, lagging behind the break in type-A cases by about 5-10 days. It is preceded by a delayed convection peak in early August and is followed by a recovery of convection in late August. Consequently, the convection shows an out of phase evolution compared with the climatological mean and type-A cases.

The preceding SST anomalies in the tropical WNP $\left(10^{\circ}-20^{\circ} \mathrm{N}, 140^{\circ}-170^{\circ} \mathrm{E}\right)$ during early and mid-July (pentads 37-41) play a crucial role in affecting the WNPSM break. The warm SST anomalies contribute to higher atmospheric instability in the lower troposphere and favor the development of convection. Consequently, active convection originates from the region of high instability and propagates westward, leading to the earlier establishment of deep convection over the WNP in late July, which is followed by the monsoon break in early August. By contrast, the cold SST anomalies induce lower atmospheric instability and suppress the development of convection, leading to a delay in the establishment of strong convection until early August and a delayed monsoon break in midAugust. In short, the SST anomalies in the tropical WNP during early and mid-July contribute to the subsequent distinct phase changes of the WNPSM by adjusting atmospheric stability.

To understand the origin of above SST anomalies impacting the WNPSM break, the related anomalies of 
the SST and circulation during the preceding seasons were examined. The results indicate that a local windevaporation-SST positive feedback mechanism during spring and summer makes a dominant contribution to the SST anomalies in the tropical WNP in midsummer. The physical process can be visualized as follows: a positive precipitation anomaly appears over the warmer SSTs and stimulates a cyclonic anomaly to the northwest as a Rossby wave response; the related westerly winds in the south of the cyclonic anomaly then weaken the mean easterly flow, decreasing evaporation and entrainment cooling, and favor the in situ SST warming. This local process of air-sea positive feedback exists after removing the variability of ENSO, suggesting that the SST anomalies in the tropical WNP during early and midJuly may originate from local air-sea interactions independent of ENSO. On the other hand, the SST anomalies in the equatorial central and eastern Pacific in the preceding winter, or the ENSO decaying phases, can also induce the SST anomalies in the tropical WNP in early and mid-July, which can be considered to have a secondary role.

Although many previous studies have documented the effects of ENSO on summer rainfall and circulation anomalies in the WNP (e.g., Wang et al. 2001; Chou et al. 2003; Wang et al. 2003; Wu et al. 2003; Wu et al. 2009; Chen et al. 2014, 2016), this study indicates that the interannual variation of the WNPSM break is significantly affected by air-sea interactions in the WNP and that this interaction in the WNP is, to a large extent, independent of ENSO. Therefore, special attention should be paid to this unique spring to summer air-sea interaction in the WNP to comprehensively understand the variability of the climate in the WNP and its effects on the East Asian summer monsoon.

Acknowledgments. The authors greatly appreciate the comments from four anonymous reviewers. This work was supported by the National Natural Science Foundation of China (Grants 41805064, 41721004, 41320104007, and 41730963) and by the Korea Meteorological Administration Research and Development Program under Grant KMIPA 2015-8070.

\section{REFERENCES}

Chen, W., R. Lu, and B. Dong, 2014: Intensified anticyclonic anomaly over the western North Pacific during El Niño decaying summer under a weakened Atlantic thermohaline circulation. J. Geophys. Res. Atmos., 119, 13 637-13650, https:// doi.org/10.1002/2014JD022199.

_ _ J.-Y. Lee, R. Lu, B. Dong, and K.-J. Ha, 2015: Intensified impact of tropical Atlantic SST on the western North Pacific summer climate under a weakened Atlantic thermohaline circulation. Climate Dyn., 45, 2033-2046, https://doi.org/ 10.1007/s00382-014-2454-4.

- - — , K.-J. Ha, K.-S. Yun, and R. Lu, 2016: Intensification of the western North Pacific anticyclone response to the short decaying El Niño event due to greenhouse warming. J. Climate, 29, 3607-3627, https://doi.org/10.1175/JCLI-D-150195.1.

Chou, C., J.-Y. Tu, and J.-Y. Yu, 2003: Interannual variability of the western North Pacific summer monsoon: Differences between ENSO and non-ENSO years. J. Climate, 16, 2275-2287, https://doi.org/10.1175/2761.1.

Du, Y., S.-P. Xie, G. Huang, and K. M. Hu, 2009: Role of air-sea interaction in the long persistence of El Niño-induced north Indian Ocean warming. J. Climate, 22, 2023-2038, https:// doi.org/10.1175/2008JCLI2590.1.

Fujinami, H., and Coauthors, 2011: Characteristic intraseasonal oscillation of rainfall and its effect on interannual variability over Bangladesh during boreal summer. Int. J. Climatol., 31, 1192-1204, https://doi.org/10.1002/joc.2146.

Gadgil, S., and P. V. Joseph, 2003: On breaks of the Indian monsoon. J. Earth Syst. Sci., 112, 529-558, https://doi.org/10.1007/ BF02709778.

Gill, A. E., 1980: Some simple solutions for heat-induced tropical circulation. Quart. J. Roy. Meteor. Soc., 106, 447-462, https:// doi.org/10.1002/qj.49710644905.

Goswami, B. N., and R. S. Ajayamohan, 2001: Intraseasonal oscillations and interannual variability of the Indian summer monsoon. J. Climate, 14, 1180-1198, https://doi.org/10.1175/ 1520-0442(2001)014<1180:IOAIVO>2.0.CO;2.

Hong, C.-C., T.-C. Chang, and H.-H. Hsu, 2014: Enhanced relationship between the tropical Atlantic SST and the summertime western North Pacific subtropical high after the early 1980s. J. Geophys. Res. Atmos., 119, 3715-3722, https:// doi.org/10.1002/2013JD021394.

Huang, G., K. Hu, and S.-P. Xie, 2010: Strengthening of tropical Indian Ocean teleconnection to the Northwest Pacific since the mid-1970s: An atmospheric GCM study. J. Climate, 23, 5294-5304, https://doi.org/10.1175/2010JCLI3577.1.

Jiang, X., and J. Li, 2011: Influence of the annual cycle of sea surface temperature on the monsoon onset. J. Geophys. Res., 116, D10105, https://doi.org/10.1029/2010JD015236.

Kanamitsu, M., W. Ebisuzaki, J. Woollen, S.-K. Yang, J. Hnilo, M. Fiorino, and G. Potter, 2002: NCEP-DOE AMIP-II Reanalysis (R-2). Bull. Amer. Meteor. Soc., 83, 1631-1643, https://doi.org/10.1175/BAMS-83-11-1631.

Kosaka, Y., S.-P. Xie, N.-C. Lau, and G. A. Vecchi, 2013: Origin of seasonal predictability for summer climate over the Northwestern Pacific. Proc. Natl. Acad. Sci. USA, 110, 7574-7579, https://doi.org/10.1073/pnas.1215582110.

Kulkarni, A., S. S. Sabade, and R. H. Kripalani, 2009: Spatial variability of intra-seasonal oscillations during extreme Indian monsoons. Int. J. Climatol., 29, 1945-1955, https://doi.org/ 10.1002/joc.1844.

- R. Kripalani, S. Sabade, and M. Rajeevan, 2011: Role of intra-seasonal oscillations in modulating Indian summer monsoon rainfall. Climate Dyn., 36, 1005-1021, https://doi.org/ 10.1007/s00382-010-0973-1.

Kumar, A., M. Chen, and W. Wang, 2013: Understanding prediction skill of seasonal mean precipitation over tropics. J. Climate, 26, 5674-5681, https://doi.org/10.1175/JCLI-D12-00731.1.

Lau, N.-C., and M. J. Nath, 2006: ENSO modulation of the interannual and intraseasonal variability of the East Asian 
monsoon-A model study. J. Climate, 19, 4508-4530, https:// doi.org/10.1175/JCLI3878.1.

Li, C., R. Lu, and B. Dong, 2014: Predictability of the western North Pacific summer climate associated with different ENSO phases by ENSEMBLES multi-model seasonal forecasts. Climate Dyn., 43, 1829-1845, https://doi.org/10.1007/ s00382-013-2010-7.

Li, K., Y. Liu, Y. Yang, Z. Li, B. Liu, L. Xue, and W. Yu, 2016: Possible role of pre-monsoon sea surface warming in driving the summer monsoon onset over the Bay of Bengal. Climate Dyn., 47, 753-763, https://doi.org/10.1007/s00382-015-2867-8.

Li, S., J. Lu, G. Huang, and K. Hu, 2008: Tropical Indian Ocean basin warming and East Asian summer monsoon: A multiple AGCM study. J. Climate, 21, 6080-6088, https://doi.org/ 10.1175/2008JCLI2433.1.

Liebmann, B., and C. A. Smith, 1996: Description of a complete (interpolated) outgoing longwave radiation dataset. Bull. Amer. Meteor. Soc., 77, 1275-1277.

LinHo, and B. Wang, 2002: The time-space structure of the AsianPacific summer monsoon: A fast annual cycle view. J. Climate, 15, 2001-2019, https://doi.org/10.1175/1520-0442(2002)015<2001: TTSSOT $>2.0 . \mathrm{CO} ; 2$.

Lu, R., and S. Lu, 2014: Local and remote factors affecting the SSTprecipitation relationship over the western North Pacific during summer. J. Climate, 27, 5132-5147, https://doi.org/ 10.1175/JCLI-D-13-00510.1.

— , and —_, 2015: Asymmetric relationship between Indian Ocean SST and the western North Pacific summer monsoon. J. Climate, 28, 1383-1395, https://doi.org/10.1175/JCLI-D14-00289.1.

— H. Hing, C.-S. Ryu, Z. Lin, and H. Dong, 2007: Midlatitude westward propagating disturbances preceding intraseasonal oscillations of convection over the subtropical western North Pacific during summer. Geophys. Res. Lett., 34, L21702, https://doi.org/10.1029/2007GL031277.

Rajeevan, M., S. Gadgil, and J. Bhate, 2010: Active and break spells of the Indian summer monsoon. J. Earth Syst. Sci., 119, 229247, https://doi.org/10.1007/s12040-010-0019-4.

Reynolds, R. W., T. M. Smith, C. Liu, D. B. Chelton, K. Casey, and M. G. Schlax, 2007: Daily high-resolution-blended analyses for sea surface temperature. J. Climate, 20, 5473-5496, https:// doi.org/10.1175/2007JCLI1824.1.

Roxy, M., and Y. Tanimoto, 2007: Role of SST over the Indian Ocean in influencing the intraseasonal variability of the Indian summer monsoon. J. Meteor. Soc. Japan, 85, 349-358, https:// doi.org/10.2151/jmsj.85.349.

Sharmila, S., S. Joseph, R. Chattopadhyay, A. K. Sahai, and B. N. Goswami, 2015: Asymmetry in space-time characteristics of Indian summer monsoon intraseasonal oscillations during extreme years: Role of seasonal mean state. Int. J. Climatol., 35, 1948-1963, https://doi.org/10.1002/joc.4100.

Singh, C., and P. Dasgupta, 2017: Unraveling the spatio-temporal structure of the atmospheric and oceanic intra-seasonal oscillations during the contrasting monsoon seasons. Atmos. Res., 192, 48-57, https://doi.org/10.1016/j.atmosres.2017.03.020.

Smith, T. M., R. W. Reynolds, T. C. Peterson, and J. Lawrimore, 2008: Improvements to NOAA's historical merged landocean surface temperature analysis (1880-2006). J. Climate, 21, 2283-2296, https://doi.org/10.1175/2007JCLI2100.1.

Tanaka, M., 1997: Interannual and interdecadal variations of the western North Pacific monsoon and Baiu rainfall and their relationship to ENSO cycles. J. Meteor. Soc. Japan, 75, 11091123, https://doi.org/10.2151/jmsj1965.75.6_1109.
Terao, T., and T. Kubota, 2005: East-west SST contrast over the tropical oceans and the post El Niño western North Pacific summer monsoon. Geophys. Res. Lett., 32, L15706, https:// doi.org/10.1029/2005GL023010.

Trenberth, K. E., and D. J. Shea, 2005: Relationships between precipitation and surface temperature. Geophys. Res. Lett., 32, L14703, https://doi.org/10.1029/2005GL022760.

Ueda, H., and T. Yasunari, 1996: Maturing process of the summer monsoon over the western North Pacific-A coupled ocean/ atmosphere system. J. Meteor. Soc. Japan, 74, 493-508, https:// doi.org/10.2151/jmsj1965.74.4_493.

_ - _ and R. Kawamura, 1995: Abrupt seasonal change of large-scale convective activity over the western Pacific in the northern summer. J. Meteor. Soc. Japan, 73, 795-809, https:// doi.org/10.2151/jmsj1965.73.4_795.

_ M. Ohba, and S.-P. Xie, 2009: Important factors for the development of the Asian-Northwest Pacific summer monsoon. J. Climate, 22, 649-669, https://doi.org/10.1175/ 2008JCLI2341.1.

Wang, B., and LinHo, 2002: Rainy season of the Asian-Pacific summer monsoon. J. Climate, 15, 386-398, https://doi.org/ 10.1175/1520-0442(2002)015<0386:RSOTAP > 2.0.CO;2.

- R. Wu, and X. Fu, 2000: Pacific-East Asian teleconnection: How does ENSO affect East Asian climate? J. Climate, 13, 1517-1536, https://doi.org/10.1175/1520-0442(2000)013<1517: PEATHD $>2.0 . \mathrm{CO} ; 2$.

- - , and K.-M. Lau, 2001: Interannual variability of the Asian summer monsoon: Contrasts between the Indian and the western North Pacific-East Asian monsoons. J. Climate, 14, 4073-4090, https://doi.org/10.1175/1520-0442(2001)014<4073: IVOTAS $>2.0 . \mathrm{CO} ; 2$.

- - , and T. Li, 2003: Atmosphere-warm ocean interaction and its impact on Asian-Australian monsoon variation. J. Climate, 16, 1195-1211, https://doi.org/10.1175/ 1520-0442(2003)16<1195:AOIAII >2.0.CO;2.

—, Q. Ding, X. Fu, I.-S. Kang, K. Jin, J. Shukla, and F. DoblasReyes, 2005: Fundamental challenge in simulation and prediction of summer monsoon rainfall. Geophys. Res. Lett., 32, L15711, https://doi.org/10.1029/2005GL022734.

_ _ B. Xiang, and J.-Y. Lee, 2013: Subtropical high predictability establishes a promising way for monsoon and tropical storm predictions. Proc. Natl. Acad. Sci. USA, 110, 2718-2722, https://doi.org/10.1073/pnas.1214626110.

Wilks, D. S., 2006: Statistical Methods in the Atmospheric Sciences. 2nd ed. Academic Press, 648 pp.

Wu, B., T. Zhou, and T. Li, 2009: Contrast of rainfall-SST relationships in the western North Pacific between the ENSOdeveloping and ENSO-decaying summers. J. Climate, 22, 4398-4405, https://doi.org/10.1175/2009JCLI2648.1.

Wu, R., 2010: Subseasonal variability during the South China Sea summer monsoon onset. Climate Dyn., 34, 629-642, https:/ doi.org/10.1007/s00382-009-0679-4.

_ set over the western North Pacific and the underlying processes. J. Climate, 13, 2483-2501, https://doi.org/10.1175/ 1520-0442(2000)013<2483:IVOSMO > 2.0.CO;2.

— and 2001: Multi-stage onset of the summer monsoon over the western North Pacific. Climate Dyn., 17, 277-289, https://doi.org/10.1007/s003820000118.

- Z.-Z. Hu, and B. P. Kirtman, 2003: Evolution of ENSOrelated rainfall anomalies in East Asia. J. Climate, 16, 3742-3758, https://doi.org/10.1175/1520-0442(2003)016<3742: EOERAI $>2.0 . \mathrm{CO} ; 2$. 
B. P. Kirtman, and K. Pegion, 2006: Local air-sea relationship in observations and model simulations. J. Climate, 19, 4914-4932, https://doi.org/10.1175/JCLI3904.1.

Xie, P., and P. A. Arkin, 1997: Global precipitation: A 17-year monthly analysis based on gauge observations, satellite estimates, and numerical model outputs. Bull. Amer. Meteor. Soc., 78, 2539-2558, https://doi.org/10.1175/1520-0477(1997)078<2539: GPAYMA $>2.0 . \mathrm{CO} ; 2$.

Xie, S.-P., and S. G. H. Philander, 1994: A coupled oceanatmosphere model of relevance to the ITCZ in the eastern Pacific. Tellus, 46A, 340-350, https://doi.org/10.3402/tellusa. v46i4.15484.

K. Hu, J. Hafner, H. Tokinaga, Y. Du, G. Huang, and T. Sampe, 2009: Indian Ocean capacitor effect on Indowestern Pacific climate during the summer following El Niño. J. Climate, 22, 730-747, https://doi.org/10.1175/ 2008JCLI2544.1.

-, Y. Kosaka, Y. Du, K. Hu, J. S. Chowdary, and G. Huang, 2016: Indo-western Pacific Ocean capacitor and coherent climate anomalies in post-ENSO summer: A review. Adv. Atmos. Sci., 33, 411-432, https://doi.org/10.1007/s00376-015-5192-6.

$\mathrm{Xu}, \mathrm{K}$., and R. Lu, 2015: Break of the western North Pacific summer monsoon in early August. J. Climate, 28, 3420-3434, https://doi.org/10.1175/JCLI-D-14-00588.1.

- , and - 2018: Decadal change of the western North Pacific summer monsoon break around 2002/03. J. Climate, 31, 177193, https://doi.org/10.1175/JCLI-D-16-0739.1.

Yang, J., Q. Liu, S.-P. Xie, Z. Liu, and L. Wu, 2007: Impact of the Indian Ocean SST basin mode on the Asian summer monsoon. Geophys. Res. Lett., 34, L02708, https://doi.org/10.1029/2006GL028571.

Yun, K.-S., K.-H. Seo, and K.-J. Ha, 2008: Relationship between ENSO and northward propagating intraseasonal oscillation in the east Asian summer monsoon system. J. Geophys. Res., 113, D14120, https://doi.org/10.1029/2008JD009901.

Zhou, W., S.-P. Xie, and Z.-Q. Zhou, 2016: Slow preconditioning for the abrupt convective jump over the northwest Pacific during summer. J. Climate, 29, 8103-8113, https://doi.org/ 10.1175/JCLI-D-16-0342.1. 